\title{
Proposição de metodologia em educação ambiental para minimizar impactos de resíduos sólidos em ecossistema de manguezal
}

\section{Resumo}

Estamos vivendo em uma época de transição econômica e de mudanças socioambientais, fomentada por hábitos inadequados no manejo dos resíduos sólidos, o que sobrecarrega os recursos naturais e a sua manutenção quanto à finitude das riquezas exploradas e degradadas, além de ameaçar a sustentabilidade do planeta. Com isso, são necessários novos métodos de educação com articulação interdisciplinar envolvendo conhecimentos científicos, de artes e de saberes locais. Nessa perspectiva, o objetivo da pesquisa foi desenvolver uma ferramenta metodológica que utilize a fotografia para sensibilização de jovens junto aos impactos ambientais trazidos pelo descarte inadequado de resíduos sólidos no ecossistema de manguezal. As imagens registradas viabilizaram a percepção e reflexão dos problemas existentes no meio em que esse grupo estava inserido, promovendo sensibilização e comprometimento na conservação dos bosques de manguezais e nas diversidades das espécies do ecossistema.

Palavras-chave: Educação Ambiental. Oficina Participativa. Imagem. Manguezal.

\section{Márcia Cristina Pinheiro Nascimento}

Mestra em Planejamento Ambiental pela Universidade Católica do Salvador - UCSAL. Brasil

marciapinheiro1202@gmail.com

\section{Cristina Maria Dacach Fernandez Marchi \\ Doutora em Geologia Ambiental pela Universidade Federal da Bahia - UFBA. Professora da \\ Universidade Católica do Salvador - UCSAL. Brasil \\ cristina.marchi@pro.ucsal.br}

\author{
Patricia Carla Barbosa Pimentel \\ Doutora em Desenvolvimento e \\ Meio Ambiente pela \\ Universidade Estadual de Santa \\ Cruz - UESC. Professora da \\ Faculdade de Tecnologias e \\ Ciências - FTC/Salvador \\ Brasil \\ patriciacbp@gmail.com
}

\footnotetext{
Para citar este artigo:

NASCIMENTO, Márcia Cristina Pinheiro; MARCHI, Cristina Maria Dacach Fernandez; PIMENTEL, Patricia Carla Barbosa. Proposição de metodologia em educação ambiental para minimizar impactos de resíduos sólidos em ecossistema de manguezal. Revista PerCursos, Florianópolis, v. 19, n.41, p. 158 - 178, set./dez. 2018.
}

DOI: 10.5965/1984724619412018158

http://dx.doi.org/10.5965/1984724619412018158 


\title{
Proposition of methodology in environmental education to minimize solid waste impacts in mangrove ecosystems
}

\begin{abstract}
We live in an age of economic transition and socioenvironmental changes which are specially driven by the effects of inadequate solid waste management practices on the preservation of natural systems, given their finiteness and the larger context of their exploitation, culminating in the endangerment of the sustainability of life on the planet. Given these challenges, it is thus necessary to develop new interdisciplinary educational methods linking science, art and local knowledge. In this perspective, the goal of this study was to develop a methodological tool based on the use of photography in the awareness-raising of youth on the environmental impacts of the inadequate disposal of solid waste in mangrove ecosystems in which the images used facilitate perception of and reflection on the related issues and challenges present in their communities and strengthen their desire to engage in the preservation of mangrove ecosystems and the species that inhabitant them.
\end{abstract}

Keywords: Environmental Education. Workshop. Image. Mangrove. 


\section{Introdução}

O acesso às temáticas econômicas, políticas e socioambientais, importantes para reflexões e mudanças, contribui para o fortalecimento da sociedade, que vive em busca da sustentabilidade equilibrada, amparada na responsabilidade e nos cuidados dos bens naturais e recursos renováveis. Mas o distanciamento ser humano frente às questões ambientais, é um fato. Fomentado, muitas vezes, pela ausência de responsabilidade e pertencimento ao meio em que vive e mergulhado no cotidiano de sobrevivência imediata e no da sua família, eleva o processo de dominação e degradação. Como diria Morin (2004, p. 38): “nós domamos a natureza vegetal e animal, pensamos ser senhores e donos da Terra".

Dado esse comportamento antropocêntrico da nossa cultura, fomentado pelo modelo econômico, de produção e de consumo desenfreado, a natureza fica exposta às negativas ações predatórias antrópicas. Isso aponta para a urgência da criação e aplicação de políticas públicas, como a Política Nacional de Resíduos Sólidos - PNRS, Lei $n^{\circ} 12.305 / 2010$, que visa um apropriado gerenciamento dos resíduos sólidos e a proteção da saúde pública e ambiental.

No Brasil, mesmo dispondo da PNRS para contribuir na resolução de problemas ambientais no manejo dos resíduos sólidos, diariamente acontece "a má disposição de resíduos sólidos das mais diversas origens, desde os mais simples, como os resíduos domésticos, até os de alta periculosidade, como os resíduos industriais, afetando diretamente os manguezais" (NASCIMENTO; PIMENTEL, 2018, p. 4).

Sabe-se que os resíduos sólidos lançados de forma irresponsável nos ecossistemas de manguezal trazem impactos negativos e degradam áreas de conservação da biodiversidade, sendo necessário um despertar urgente para as mudanças requeridas. Segundo Morin (2006, p. 34), “cuidar do destino planetário do gênero humano se torna cada vez mais indispensável a cada um e a todos nós, pois isso deve ser um dos principais objetos da educação", o que torna necessário um sistema de educação renovado, fundamentado no cuidado, reconhecimento e conhecimento das relações entre sociedade e meio ambiente. 
Uma das dificuldades encontradas para a promoção da Educação Ambiental é a ausência de metodologias e procedimentos didáticos que sejam interdisciplinares (APA, 2006). Sendo assim, em tempos de uso da tecnologia e de surgimento de novos conhecimentos, torna-se apropriada a busca por novas metodologias, fundamentadas em experiências cotidianas, mobilizadoras e participativas, objetivando novas percepções e o comprometimento com o meio ambiente e a sociedade.

No contexto de uma sociedade contemporânea, considerada como uma civilização de símbolos e imagens, o desenvolvimento tecnológico pode ser um facilitador de novas visões, conhecimentos e mudanças. Nesses termos, Campos et al. (2000) ressaltam o uso da tecnologia na conservação da natureza, sinalizando para o avanço tecnológico cada vez mais acelerado que possibilita ao ser humano conhecer os processos ecológicos mais profundamente. Todavia, existe pouco interesse no uso da tecnologia como ferramenta pedagógica acessível a todos na contemporaneidade. O aparelho celular, por exemplo, geralmente possui câmera fotográfica, que pode proporcionar o aparecimento de novos processos e o enriquecimento de oportunidades educacionais junto ao meio ambiente, o que beneficia uma possível relação equilibrada com a natureza.

O uso da fotografia no campo da educação ambiental vislumbra tema fértil "para o diálogo, pois a fotografia é um recurso comunicativo midiático cada vez mais difundido, em grande parte pela internet e redes sociais" (HOFSTATTER; OLIVEIRA, 2015, p. 92). A fotografia nos faz pensar e compreender que "o homem não pode ser separado do universo e sim situado nele, pois quem somos é inseparável de onde estamos, de onde viemos e para onde vamos" (SILVA, 2007, p. 61). Corroborando, Sato e Passos (2009) consideram que uma imagem provoca linguagens. "que mostram o controverso das coisas e que também nos convida a repensar modelos de desenvolvimento, conflitos socioambientais ou identidades em transe nos territórios de lutas" (SATO; PASSOS, 2009, p. 49).

Portanto, a fotografia é uma ferramenta que pode "produzir leituras críticas, assim como suscitar reflexões sobre a realidade apresentada" (GONZALEZ et al., 2017, p. 3). Isso trilha novos caminhos de integração, reflexão e consciência do cotidiano social e 
ambiental, com perspectivas de mudanças comportamentais e de sensibilização e comprometimento com a conservação de manguezais.

Diante do exposto, o objetivo da pesquisa aqui relatada foi desenvolver uma ferramenta metodológica que utilize a fotografia para sensibilização de jovens no que se refere aos impactos ambientais trazidos pelo descarte inadequado de resíduos sólidos no ecossistema de manguezal.

\subsection{A política nacional de resíduos sólidos e educação ambiental}

Com a Revolução Industrial, as inquietações sobre o acúmulo, destino e gerenciamento dos resíduos sólidos urbanos, domésticos e industriais foram crescendo à medida que a população percebia a extensão de prejuízos para sociedade, apontando a necessidade de normativas reguladoras para o descarte dos resíduos. No entanto, foi na década de 1970 que a preocupação em relação ao meio ambiente e à questão dos resíduos sólidos começou a ganhar mais força. Em 1972, a Organização das Nações Unidas - ONU promoveu a Conferência das Nações Unidas sobre o Meio Ambiente Humano (CNUMAH) e, nessa ocasião, foram criadas as primeiras políticas públicas voltadas para a coleta e disposição final dos resíduos sólidos, dando seguimento à elaboração de diversos decretos e leis (TAVARES, 2008).

O Brasil, por sua vez, já tem sua Política Nacional de Resíduos Sólidos (PNRS), a lei federal $n^{\circ}$ 12.305, de 2 de agosto de 2010, que trata e direciona questões ambientais, econômicas e sociais relacionadas com o manejo dos resíduos gerados (NASCIMENTO; PIMENTEL, 2018). Com a sanção da PNRS, o Brasil passa a ter um marco regulatório na área dos resíduos sólidos, que permite desenvolvimento e mudanças na situação populacional principalmente no que se refere a saneamento básico, trazendo alento e respaldo à luta pela sustentabilidade, além de prever mecanismos para o maior equilíbrio entre o desenvolvimento social, econômico e ambiental (RAUBER, 2011).Tendo em vista as ações de manejo dos resíduos sólidos das cadeias produtivas, a PNRS recomenda acordos entre diversas esferas, como os acordos setoriais entre o governo e as cadeias produtivas e a logística reversa. Nascimento e Pimentel (2018) ressaltam a importância da 
integração das Políticas de Educação Ambiental e de Resíduos Sólidos para o sucesso de uma efetiva implementação das suas recomendações.

Nas disposições da PNRS, a Educação Ambiental é ressaltada, no capítulo III, como um instrumento de grande importância para o adequado gerenciamento dos resíduos sólidos no país. Nesse marco regulatório, seção IV - Dos Planos Municipais de Gestão Integrada de Resíduos Sólidos, artigo 19, inciso X, são recomendados programas e ações de educação ambiental na gestão de resíduos sólidos que promovam a não geração, a redução, a reutilização e a reciclagem de seus resíduos com a sustentabilidade (BRASIL, 2010).

A PNRS, ao dispor a Educação Ambiental como instrumento relevante de gestão, estabelece importante relação com a Política Nacional de Educação Ambiental - PNEA, incluindo a estrutura de princípios, diretrizes e categoria de educação ambiental formal e não formal, como norteadoras de sensibilização ambiental, contribuição socioambiental, transformação de responsabilidade e participação no manejo adequado e gerenciamento dos resíduos sólidos.

Os projetos de Educação Ambiental tendem a ser categorizados em duas vertentes de trabalho: a Educação Ambiental Crítica e a Educação Ambiental Conservadora ou Tradicional. Guimarães (2004) considera que a vertente conservadora, ao elaborar e praticar seus projetos de Educação Ambiental, não considera a vivência, o meio social e os conhecimentos que seus atores já possuem ao aplicar conceitos e práticas tecnicistas sobre aspectos importantes para diálogos e reflexões. Contrária à vertente tradicional, a Educação Ambiental Crítica se interliga com a Educação Ambiental não formal. Possui ações e ferramentas de manifestos utilizadas pelos seus colaboradores em oposição aos padrões cartesianos. “Critica e aponta para transformações nas relações de produção, nas relações sociais, nas relações homemnatureza, na relação homem-subjetividade, num processo de construção coletiva de uma ética, uma nova cultura, novos conhecimentos" (GUIMARÃES, 2000, p. 84).

A Educação Ambiental Crítica se refere à democracia dos direitos, o que não despreza ou descarta algumas ações de linha conservadora. Trabalha em paralelo às duas 
vertentes da educação ambiental (crítica|conservadora). Nunes (2015) adverte que, atualmente, existem inúmeros projetos em andamento de Educação Ambiental no Brasil cujos princípios pedagógicos oscilam entre as duas vertentes epistemológicas citadas, com resultados satisfatórios.

Existem escolas, em território brasileiro, em parcerias com organizações não governamentais - ONGs, que focam as práticas da educação no conhecimento, experiência e aprendizado, aproximando a escola à realidade local. Uma dessas práticas trata os ecossistemas como área física ondeo ser humano e as outras espécies vivem e preenchem todas suas necessidades.

\subsection{Metodologias que apoiam a educação ambiental em ecossistemas de manguezal}

As técnicas da fotografia ainda são pouco discutidas, mas adotadas nos últimos tempos, com boa aceitação, alcançando resultados positivos no desenvolvimento de pesquisas e projetos ambientais. No âmbito de referências metodológicas com uso da fotografia, Silveira e Alves (2008) desenvolveram um estudo intitulado "O Uso da Fotografia na Educação Ambiental: Tecendo Considerações”. As autoras investigaram as contribuições da arte pelo uso da fotografia como recursos metodológicos e educativos em Educação Ambiental para formação de sujeitos participativos e atuantes no processo socioambiental.

Nas contribuições da fotografia como técnica metodológica, Farias e Matos (2012) realizaram um trabalho na área da saúde: "Oficina de Fotografia como Veículo de Educação Ambiental e em Saúde: Exemplo da Favela do DETRAN, Natal-RN”. O foco desse trabalho foi discutir, a partir de fotografias, as relações entre o ambiente e a saúde local.

Nunes (2012) considera de grande relevância as fotografias do jornalista e fotógrafo Sebastião Salgado, da obra Genesis, publicada em 2003, que mostra imagens de continentes e diversidades de espécies, apresenta conteúdo de grande relevância e abordagens de percepção visual e reflexão comportamental para a conservação ambiental. Essa obra, desde sua publicação, vem contribuindo em programas de pesquisas acadêmicas e projetos de Educação Ambiental. O Projeto Educacional Genesis 
foi iniciado em 2005 pelo Instituto Terra, em Minas Gerais e baseia-se em fotografias produzidas por Sebastião Salgado justamente coma finalidade de sensibilizar as pessoas à reflexão sobre as relações homem-natureza. Paisagens físicas e humanas registradas pelo fotógrafo Sebastião Salgado em expedições pelo mundo dentro do projeto Genesis deram forma e conteúdo ao Projeto Educacional de mesmo nome, que no ano de 2012 envolveu 165 professores atuantes nas unidades de ensino públicas e privadas no município mineiro de Resplendor- MG (NUNES, 2012).

Considerando as explorações interdisciplinares de práticas ligadas à Educação Ambiental, diversas ferramentas educacionais vêm sendo desenvolvidas com novos formatos e dinâmicas criativas de ação e participação, inclusive com foco na percepção e conservação do manguezal. Algumas podem ser citadas, como as tratadas por Dias (2010), que relatam 33 dinâmicas e 22 instrumentações para Educação Ambiental a serem aplicadas junto a um público de qualquer idade. Passos (2013) cita o trabalho "Práticas em Educação Ambiental", no qual são apresentadas 70 atividades relacionadas ao tema. Ela afirma que essas atividades favorecem a aproximação do educando ao meio ambiente, estimulam percepções e inter-relações criativas e permitem um olhar de respeito e pertencimento.

Dada a extensão dos problemas, existem lacunas extensas precisando ser preenchidas por meio de ações participativas de colaboradores e segmentos que unam comunicação e educação. O celular e a internet são destacados como mídias de grande poder comunicativo da sociedade.

Talomani et al. (2018) citam o poder comunicativo da internet:

Outro veículo de grande penetração na comunidade é a internet, uma fonte de bons sites direcionados à Educação Ambiental, onde podem ser encontradas informações sob a forma de texto, fotos, desenhos, vídeos e demais arquivos multimídia. Entre eles destacamos: Associação Projeto APOEMA - Educação Ambiental (www.apoema.com.br); Instituto ECOAR para a Cidadania (www.ecoar.org.br); United States Environmental Protection Agency - EPA (www.epa.gov); Programa Criança Ecológica, da Secretaria do Meio Ambiente do Estado de São Paulo (www.criancaecologica.sp.gov.br); Instituto ARGONAUTA para a 
Conservação Costeira e Marinha (www.institutoargonauta.org); entre outros. (TALOMANI et al., 2018, p. 69).

A partir do exposto, percebem-se as várias nuances de métodos e buscas para inovações de suporte e contribuição em projetos e ações de Educação Ambiental, permeando a proteção da saúde humana e ambiental através da sensibilização e colaboração dos envolvidos, como proposto pela PNRS.

\section{Contextualização da área de estudo}

O estudo foi realizado no distrito do Mutá (do tupi-guarani, "lugar de todos"), comunidade tradicional de pescadores e marisqueiras pertencente ao município de Jaguaripe, a $101 \mathrm{~km}$ de Salvador, Bahia. O ecossistema predominante é o manguezal, e o município recebeu o título de Pantanal Baiano (SANTOS, 2016).

Mutá tem população aproximada de 600 habitantes (IBGE, 2010), sendo quase todos os residentes pescadores artesanais, o que reflete a principal atividade econômica da comunidade: pesca e a exploração de recursos naturais da Mata Atlântica e do manguezal, para confecção e venda de peças artesanais. Está situada em uma Unidade de Conservação de Uso Sustentável, abrangida pela riqueza biológica dos manguezais que constituem a fonte do sustento de inúmeras famílias, e onde reside o conflito entre a degradação e a conservação dos recursos naturais.

Os moradores de Mutá têm orgulho de sua história e cultura e se reconhecem como uma comunidade diferenciado na estrutura constituída de comunidade tradicional.A categoria de comunidade tradicional de pescadores e marisqueiras lhes atribui o direito de receber apoio como o auxílio defeso, política específica de conservação local e valorização da categoria. 


\section{Aspectos metodológicos}

O estudo se classifica como qualitativo investigativo e experimental, e se deu em duas etapas: o concurso de fotografia e a oficina ambiental no manguezal. Essas etapas buscavam compreender e sensibilizar, respectivamente, sobre o ecossistema de manguezal, que é a principal fonte de recursos econômicos e culturais da comunidade do Mutá.

(i) Primeira Etapa: nos dias 15 e 16 de agosto de 2016, foi realizado pela Associação dos Moradores do Mutá - AMMU, em parceria com a Universidade Católica do Salvador UCSAL, o concurso de fotografia intitulado "O Mangue e Eu". Esse concurso teve a participação de 14 jovens associados, com faixa etária de 10 a 15 anos, que atenderam ao convite feito anteriormente, por meio de cartazes, e que divulgavam para os possíveis participantes da associação comunitária a realização de um concurso de fotografia com o tema manguezal. Na data marcada, foram realizadasduas visitas ao manguezal e solicitado que os jovens levassem seus celulares para que pudessem tirar as fotos do que mais Ihes chamava a atenção naquele ecossistema.

(ii) Segunda Etapa: nos dias 24 e 25 de setembro de 2016, foi realizada a oficina ambiental no manguezal, que foi conduzida na Associação dos Moradores do Mutá AMMU, com a participação de suas coordenadoras e dos jovens que participaram do concurso fotográfico. Para o planejamento da oficina, foram escolhidas e aplicadas cinco dinâmicas pertinentes ao tema proposto.

\section{Resultados encontrados a partir do encadeamento das etapas metodológicas}

Na primeira etapa, na sede da AMMU, foi iniciado o processo do concurso de fotografia "O Mangue e Eu”. A importância da imagem do celular foi explicada, buscando enaltecer a conservação do manguezal. Houve uma breve recomendação sobre possíveis impactos do "lixo" e a necessidade dos participantes registrarem como eles percebiam aqueles impactos. Posteriormente, foram realizadas as visitas às áreas do manguezal com 
duas turmas, uma pela manhã, outra à tarde, com a produção de imagens dos aparelhos celulares. As áreas visitadas se encontravam bastante impactadas por resíduos de diversas origens e tipos: da construção civil, de embalagens plásticas, de metais, de vidros, de pedaços de redes de pesca, dentre outros.

Após as visitas, o concurso foi desenvolvido em três fases, descritas a seguir:

(i) Primeira Fase: Análise interna das fotografias produzidas

As imagens geradas pelos jovens, no manguezal, instigaram a curiosidade da maioria do grupo a respeito da fauna e flora locais. Foi solicitado que cada participante indicasse a foto que mais lhe agradava e descrevesse o que percebia no ambiente da imagem escolhida. De acordo com Gomes (1996), ao registrar a experiência, a imagem fotográfica pode provocar novas percepções, produzir a subjetividade inerente ao ato de olhar e imortalizar o fato e o espaço captados, contextualizando-os.

Após a escolha, cada participante colocou, na imagem, seu nome, idade e série escolar cursada. Algumas imagens e seus descritores estão apresentados na Figura 1, a seguir:

Figura 1 - Painel com imagens escolhidas pelos participantes do concurso de fotografia

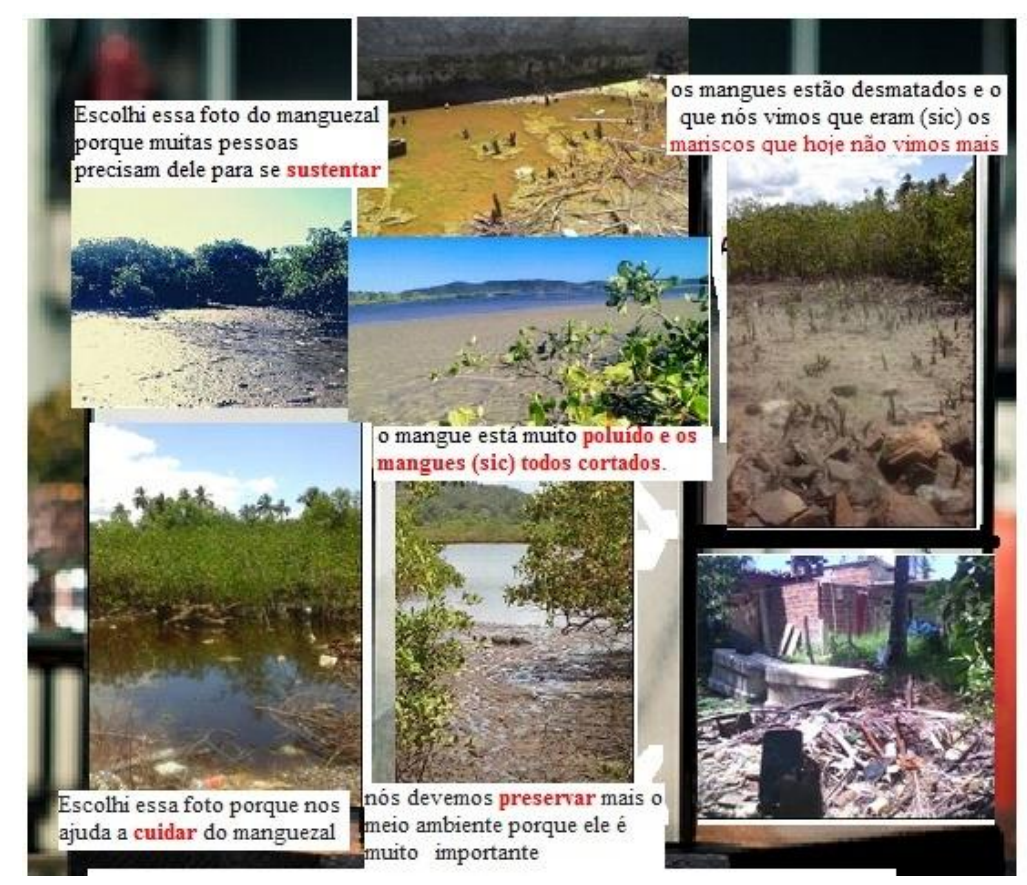

Fonte: Elaborado pela autora 
(ii) Segunda Fase: Comparativo entre as percepções de especialistas e dos participantes

A segunda fase se deu por meio de uma consulta, por e-mail, a 23 pessoas brasileiras e estrangeiras, que ocupam funções ligadas à imagem, ao meio ambiente e à educação, visando explorar percepções trazidas pelas 14 fotografias selecionadas na primeira fase. O critério de análise exigiu que esses especialistas utilizassem termos objetivos e que enviassem três palavras que descrevessem as imagens visualizadas, também levando em conta as descrições elaboradas pelos autores das fotografias. Os termos solicitados foram agrupados mediante categorias para serem trabalhadas em oficinas ambientais no ecossistema manguezal. Aqueles que mais apareceram nas descrições dos especialistas são apresentados na Tabela 1, a seguir:

Tabela 1 - Termos recorrentes vislumbrados por especialistas diante das imagens escolhidas pelos participantes do concurso de fotografia “O Mangue e Eu” - Mutá, Jaguaripe, Bahia (2017)

\begin{tabular}{cl}
\hline $\mathbf{N}^{\circ}$ de Ordem & Termos escolhidos por especialistas \\
\hline $\mathbf{1}$ & Beleza e Sossego \\
$\mathbf{2}$ & Extinção das Espécies \\
$\mathbf{3}$ & Desmatamento \\
$\mathbf{4}$ & "Lixo" \\
$\mathbf{5}$ & Importância da Preservação \\
$\mathbf{6}$ & Cuidado \\
$\mathbf{7}$ & Coletividade \\
$\mathbf{8}$ & Patrimônio \\
\hline
\end{tabular}

Fonte: Elaborado pela autora

Com os termos obtidos pela consulta aos especialistas e com as descrições das fotografias pelos jovens, foram construídas duas categorias de análise:

(i) Distanciamento do problema: entendido como imagens e descritores dos participantes que não focalizavam os impactos evidenciados pelo descarte inadequado dos resíduos no manguezal e;

(ii) Aproximação do problema: imagens e descritores que focavam os impactos trazidos pela ausência de descarte adequado no manguezal. 
Proposição de metodologia em educação ambiental para minimizar impactos de resíduos sólidos em ecossistema de manguezal

Márcia Cristina Pinheiro Nascimento, Cristina Maria Dacach Fernandez Marchi. Patricia Carla Barbosa Pimentel

As figuras, apresentadas a seguir, demonstram as categorias de análise escolhidas pelo estudo (baseadas nas imagens mais significativas) e os descritores dos participantes (Figuras 2, 3, 4, 5, 6, 7).

\section{Distanciamento}

Figura 2 - Categoria Beleza e Sossego Título: Escolhi a foto pela beleza natural

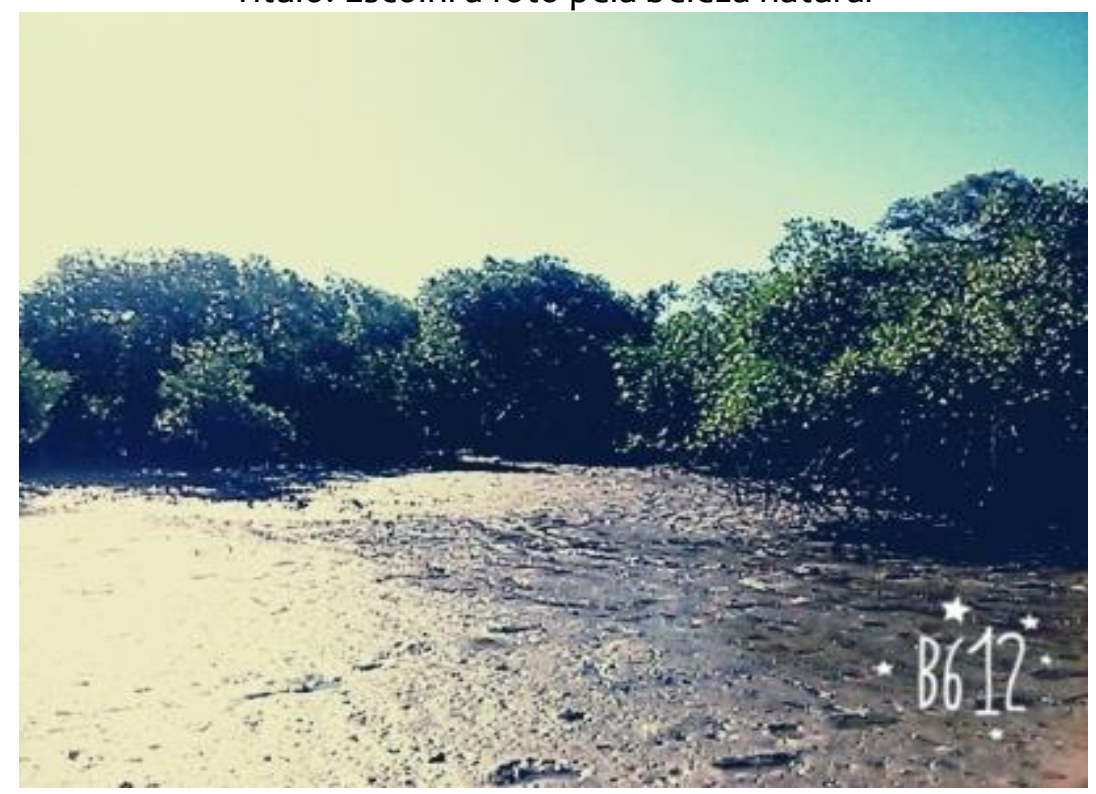

Fonte: Stefane, 14 anos, 2016

Figura 3 - Categoria Beleza e Sossego

Título: Escolhi essa foto, pois ela me traz a beleza dos manguezais e o sossego do mar

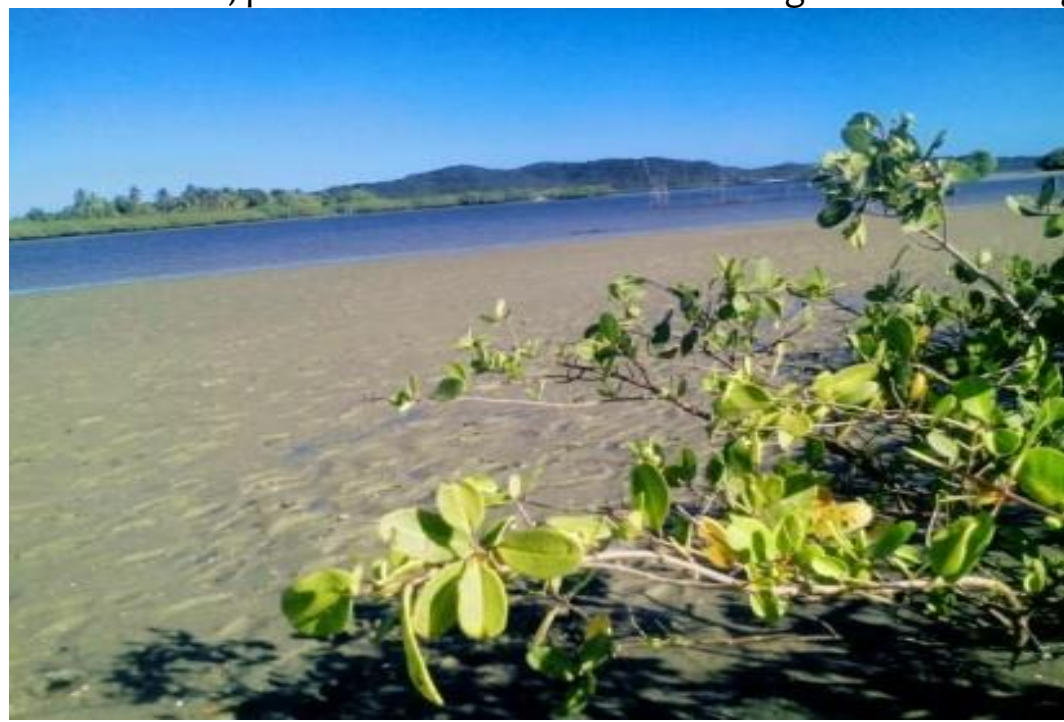

Fonte: Liliane, 14 anos, 2016 
Proposição de metodologia em educação ambiental para minimizar impactos de resíduos sólidos em ecossistema de manguezal

Márcia Cristina Pinheiro Nascimento, Cristina Maria Dacach Fernandez Marchi. Patricia Carla Barbosa Pimentel

Figura 4 - Categoria Beleza e Sossego

Título: Escolhi essa foto porque foi a paisagem mais bonita que achei em todo manguezal

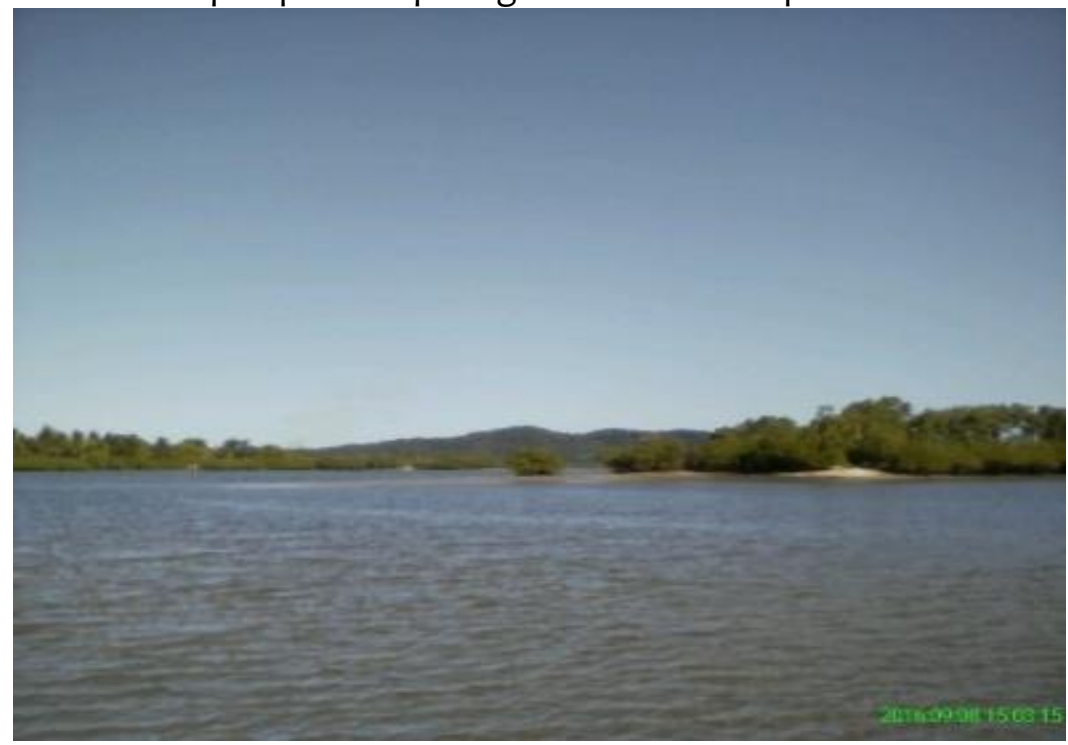

Fonte: Ingrid, 12 anos, 2016

\section{Aproximação}

Figura 5 - Categorias Lixo e Cuidado.

Título: Escolhi essa foto para conscientizar as pessoas que jogam lixo no manguezal

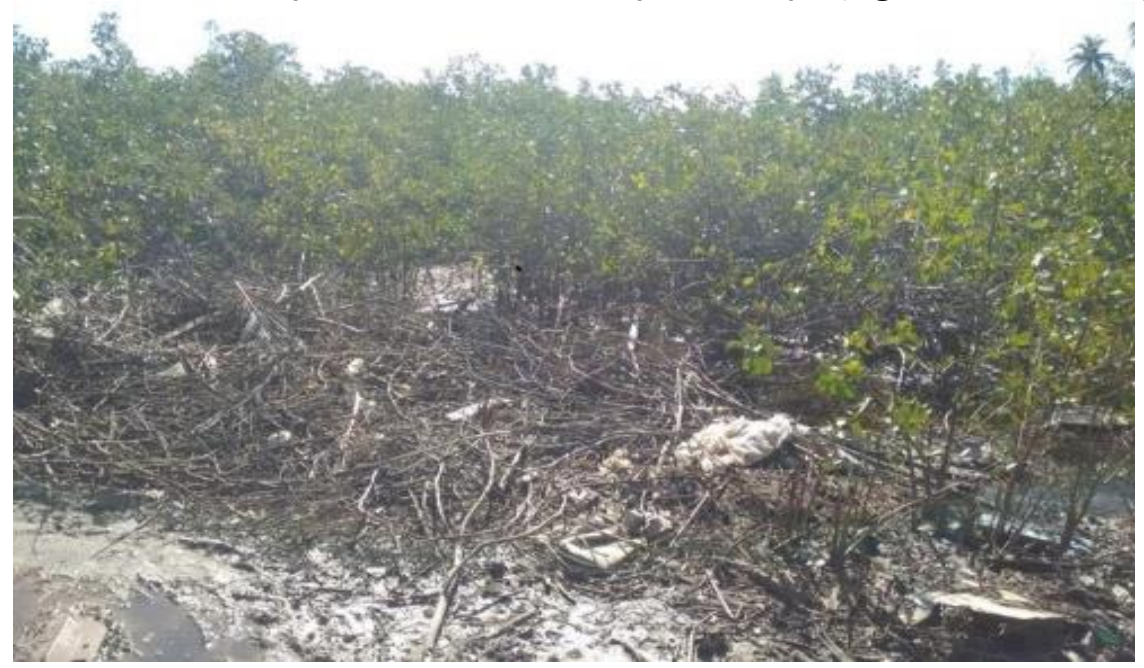

Fonte: Amanda, 13 anos, 2016 
Proposição de metodologia em educação ambiental para minimizar impactos de resíduos sólidos em ecossistema de manguezal

Márcia Cristina Pinheiro Nascimento, Cristina Maria Dacach Fernandez Marchi. Patricia Carla Barbosa Pimentel

Figura 6 - Categorias Extinção das Espécies e Desmatamento.

Título: Escolhi essa foto porque os mangues estão desmatados e o que nós víamos antes que era muito marisco, hoje não vemos mais

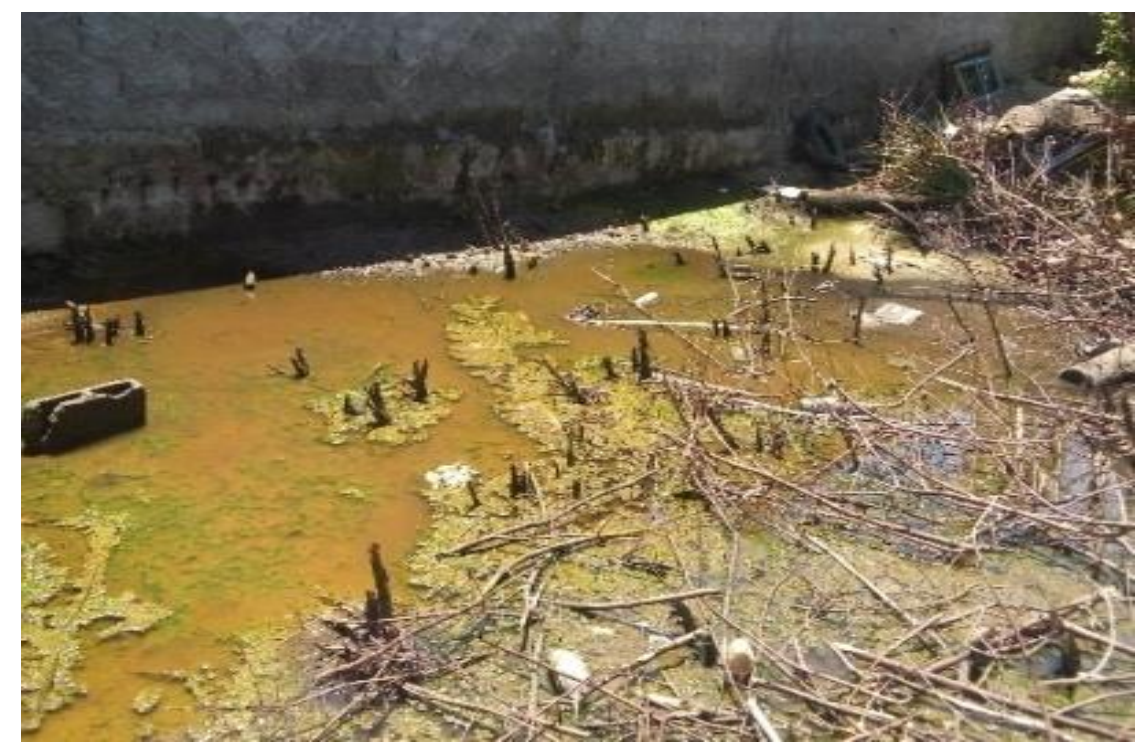

Fonte: Ruanderson,14 anos, 2016

Figura 7 - Categorias Coletividade, Patrimônio e Importância da Preservação. Título: Escolhi essa foto para mostrar o patrimônio ambiental que temos

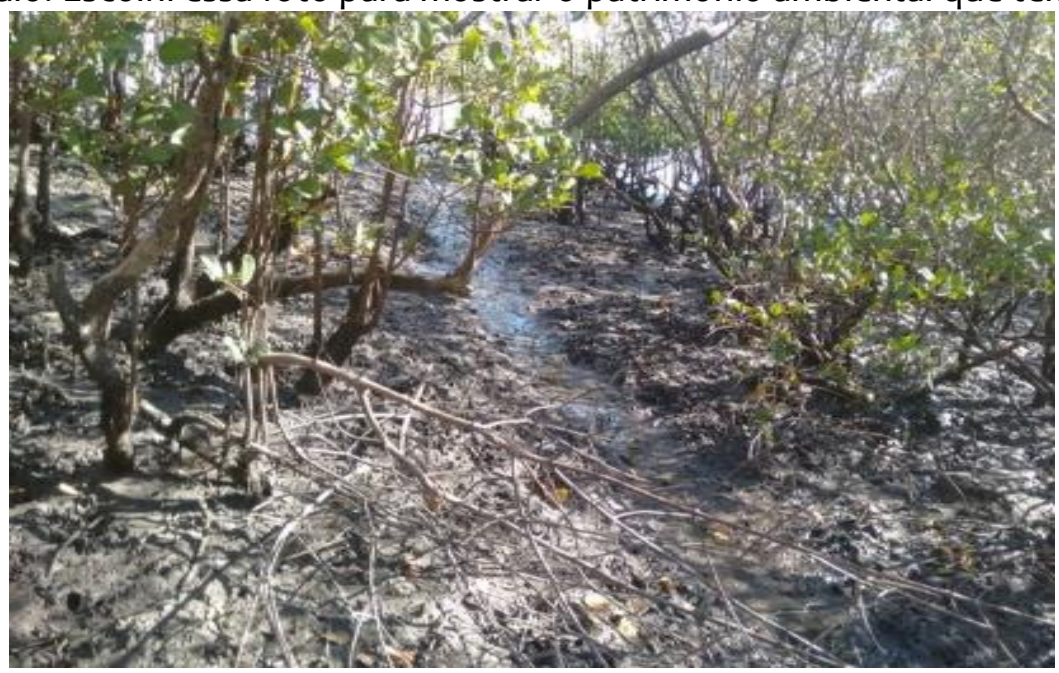

Fonte: Flavio, 12 anos, 2016 
(iii) Terceira Fase: Análise e premiação dos vencedores

Devido ao envolvimento dos jovens e para incentivar sua disposição, todos os participantes foram premiados com uma viagem a Salvador. No dia 18 de outubro de 2016, acompanhados pelas coordenadoras e professoras da AMMU, eles tiveram a oportunidade de apreciar suas fotografias expostas em um mural, no campus de Pituaçu da UCSAL, durante o Salão Interativo da $19^{\text {a }}$ Semana de Movimentação Científica SEMOC, cujo tema era "Natureza e Sociedade". Todos tiveram a oportunidade de conhecer a universidade, de participar de trilha ecológica, da apresentação de trabalhos científicos, de oficinas de jogos interativos e outras exposições e atividades do evento.

Na segunda etapa, ocorreu a Oficina Ambiental no Manguezal, dando seguimento à ação iniciada no concurso de fotografia, que apresentou um grande potencial de conhecimento e sensibilização voltados para as questões socioambientais da comunidade; a importância de aproveitar os resultados foi percebida e, então, foi planejada uma oficina ambiental no manguezal.

A oficina foi conduzida durante os dias 24 e 25 de setembro de 2016, na Associação dos Moradores do Mutá - AMMU, com a participação aberta à comunidade. Durante a “Oficina Ambiental no Manguezal”, foram aplicadas cinco dinâmicas: a Caixa Surpresa (cujo objetivo foi aguçar a percepção ambiental e introduzir conceitos e a importância dos elementos que compõe o ecossistema do manguezal). Foi colocada uma caixa sobre a mesa com objetos encontrados no ecossistema local, em especial, folhas de plantas do manguezal, galhos secos, conchas, fragmentos de corais, saco plástico, garrafa vidro, pedaços de nylon, caixa de margarina, entre outros. Com os olhos vendados, solicitou-se aos jovens que colocassem as mãos na caixa e retirassem um objeto, tocassem, sentissem, cheirassem e tentassem descrever para o grupo. Para a Dinâmica do Espelho cujo objetivo era o despertar em cada jovem o que seria o elemento das mudanças locais, foi utilizada uma caixa quadrada com tampa fechada e dentro dela havia um espelho grande. Primeiramente foi solicitado que os jovens pensassem sobre de que forma/ ferramentas/ instrumentos eles desejariam para mudar a situação do manguezal e local. Após pensar sobre e verbalizar seu desejo, o jovem era orientado a abrir a caixa e ver por meio do espelho, a forma/ferramenta de mudança da realidade do manguezal e local. 
Para a Exposição das Fotografias foi criado um mural expondo as fotos do concurso, com os nomes dos autores das fotos. As imagens expostas revelaram as inquietações do grupo. Os jovens foram provocados a expor os sentimentos e olhares para o ambiente local e o que motivaram a escolha de cada fotografia. O objetivo desta dinâmica foi desencadear as inquietações, verbalizações e comportamentos através das fotografias, bem como a valorização do olhar do jovem sobre a sua realidade local. Enfrentando Desafios (dinâmica da caixa com barra de chocolates), teve como objetivo demonstrar a importância de enfrentar os desafios de maneira responsável e em coletividade. Antes de passar a caixa foi proposta uma conversa sobre a questão ambiental como um desafio a ser enfrentado para se ter um ambiente melhor e naquele momento um deles iria receber o desafio. Em uma caixa de papelão foram colocadas barras de chocolates. Depois lacrada a caixa, colocou-se a frase "enfrentando desafios". O grupo de jovens foi organizado em círculo e foi colocada uma música. A medida que a música era tocada a caixa circulava passando de mão em mão. Quando a música parava tocar, nas mãos de quem estava a caixa, este era responsável pelo desafio proposto. Antes de abrir a caixa era necessário que o jovem falasse ao grupo como ele enfrentaria o desafio. Em seguida, abriu-se a caixa de papelão e as barras de chocolate foram divididas com todos participantes do círculo. A União Faz a Força cujo objetivo foi conscientizar sobre a importância de cada indivíduo cuidar do meio ambiente com a participação coletiva, contribuindo para um viver melhor. Foram divididos pedaços de papelão de tamanhos variados espalhados no chão. Os jovens foram convidados a se posicionarem sobre os pedaços de papelão e formou-se um círculo. Ao som da música eles iam girando no círculo e pedaços do papelão foram retirados do círculo. Quando a música parava eles tinham que estar com os pés sobre papelão, não era permitido ter os pés no chão. Ao final ficou um só papelão e todos fizeram o esforço de ficar sobre ele; abraçados, de um pé só, um em cima do pé do outro.

Ao participar das dinâmicas, os jovens foram provocados a exporem seus sentimentos e olhares para com o ambiente local e o que os levou às escolhas das suas fotografias, o que resultou em maior entendimento e interação de todos os participantes para com os temas tratados. As narrativas dos jovens surgiram, espontaneamente, plenas de conteúdos apropriados para a adequada percepção da situação negativa no descarte 
dos resíduos sólidos no manguezal do Distrito do Mutá. De acordo com Justo (2003), uma oficina de fotografia e a disponibilidade para se trabalhar a noção de pertencimento do grupo facilitam a escuta e interação dos envolvidos nas contribuições e permitem que eles desenvolvam um novo olhar.

Em resposta às dinâmicas aplicadas durante a Oficina Ambiental no Manguezal, foi desencadeada uma série de sugestões para novos comportamentos e atitudes necessários na comunidade, visando minimizar os danos ambientais existentes e a ocorrência de novos processos de degradação.

A utilização da fotografia como meio de percepção ambiental apontou para ações desafiadoras e contínuas. Borges, Aranha e Sabino (2010) afirmam que a utilização da fotografia não é apenas um meio de informações e documentações visuais, mas também oportuniza a aplicação dessas imagens como forma de mudança de comportamentos e atitudes em relação aos problemas ambientais e ecológicos.A técnica de fotografia utilizada na pesquisa proporcionou percepção, reflexão, interpretações e, por fim, levou o grupo a diagnosticar a situação do ecossistema manguezal do seu distrito, o que caracteriza a ferramenta desenvolvida como fotodiagnóstico.

\section{Considerações finais}

Considerando o objetivo de desenvolver uma ferramenta metodológica que utilizasse a fotografia para sensibilização de jovens no que se refere aos impactos ambientais trazidos pelo descarte inadequado de resíduos sólidos no ecossistema de manguezal, observou-se que a utilização da fotografia, neste estudo, possibilitou uma maior interação do grupo junto aos problemas ambientais locais, principalmente os referentes ao descarte inadequado dos resíduos sólidos.

Nesse sentido, o fotodiagnóstico foi considerado apropriado como uma ferramenta educacional, pois superou as expectativas da pesquisa em virtude dos resultados alcançados, uma vez que possibilitou o desenvolvimento de percepção, 
reflexão, interpretação acerca de uma problemática presente na comunidade, levando o grupo a diagnosticar a situação do ecossistema manguezal.

A proposição de ferramenta metodológica com forte impacto educacional, sobretudo no que diz respeito à educação ambiental, com o uso da fotografia, que visou uma nova percepção sobre os impactos de resíduos sólidos no ecossistema de manguezal, aponta para novos estudos que validem os resultados aqui encontrados. É válido ressaltar que reaplicar a metodologia que utiliza a fotografia como ferramenta de educação ambiental pode contribuir para promover mudanças de percepção sobre o ecossistema de manguezal, provedor de nutrientes para as espécies e indispensável para o equilíbrio ecológico e para a sustentabilidade de comunidades do seu entorno.

\section{Referências}

APA, Hatsi Corrêa Galvão do Rio. A utilização da arte como ferramenta para educação ambiental. Universidade Federal de Santa Catarina - UFSC, Departamento de Zootecnia e Desenvolvimento Rural, Disciplina de Projetos e Seminários. Santa Catarina, 2006.

BORGES, Marília Dammski; ARANHA, José Marcelo; SABINO, José. A fotografia de natureza como instrumento para educação ambiental. Ciência \& Educação, v. 16, n. 1, p. 149-161, 2010.

BRASIL. Lei n 12.305, de 02 de agosto de 2010. Altera a Lei no 9.605 , de 12 de fevereiro de 1998 e dá outras providências.Política nacional de resíduos sólidos. Brasília, DF, 2010. Disponível em: www.planalto.gov.br. Acesso em: 23 abr. 2017.

CAMPOS, Marília Menezes Freitas de et al. Educação ambiental e paradigmas de interpretação da realidade: tendências reveladas. 2000.389 p. Tese (Doutorado em Educação) - Faculdade de Educação, Universidade Estadual de Campinas, Campinas, SP.

DIAS, Genebaldo Freire. Dinâmicas e instrumentação para educação ambiental. São Paulo: Gaia, 2010. 215 p.

FARIAS, Tadeu Mattos; MATOS, Anna Carolina Vidal. Oficina de fotografia como veículo de educação ambiental em saúde: exemplo da favela do DETRAN, Natal-RN. Revista eletrônica do mestrado em educação ambiental - REMEA, v. 28, 2012. 
GOMES, Patrícia. Da escrita a imagem: da fotografia à subjetividade. 1996. Dissertação (Mestrado em Psicologia) - Institituto de Psicologia, Universidade Federal do Rio Grande do Sul, Porto Alegre.

GONZALEZ, Ana Helena Grieco; ROCHA, Marcelo Borges; REGO, Sheila Cristina Ribeiro. Uso da fotografia como ferramenta para a percepção ambiental sobre a Baía de Guanabara. In: ENCONTRO NACIONAL DE PESQUISA EM EDUCAÇÃO EM CIÊNCIAS, 11., 2017, Florianópolis. Anais[...] Florianópolis: Universidade Federal de Santa Catarina, 2017.

GUIMARÃES, Mauro. Por uma educação ambiental crítica. In:GUIMARÃES, Mauro.

Educação ambiental: no consenso um embate? Campinas: Ed. Papirus, 2000. p. 67-85.

GUIMARÃES, Mauro. Educação ambiental crítica.In: IDENTIDADES da educação ambiental brasileira.Brasília: Ministério do Meio Ambiente, p. 25-34, 2004.

HOFSTATTER, Lakshmi Juliane Vallim; OLIVEIRA, Haydée Torres de. Olhares perceptivos: usos e sentidos da fotografia na educação ambiental. Pesquisa em Educação Ambiental, v. 10, n. 2, p. 91-108, 2015.

IBGE, Censo Demográfico Município Jaguaripe Bahia, 2010. Disponível em: http://www.censo2010.ibge.gov.br/sinopse/index. Acesso em: 12 mai. 2016.

JUSTO, Carmen Sílvia Sanches. Os meninos fotógrafos e os educadores: viver na rua e no Projeto Casa. São Paulo: UNESP, 2003.

MORIN, Edgar. A cabeça bem-feita. 9. ed. Rio de Janeiro: Bertrand Brasil, 2004. Tradução de: Eloá Jacobina.

MORIN, Edgar. Os sete saberes necessários à educação do futuro. 11. ed. São Paulo: Cortez; Brasília, DF: UNESCO, 2006.

NASCIMENTO, Márcia Cristina Pinheiro; PIMENTEL, Patrícia Carla Barbosa. Educação ambiental e os impactos dos resíduos sólidos no ecossistema manguezal. In: MARCHI, Cristina Maria Dacach Fernandez (Org.). Gestão dos resíduos sólidos: conceitos e perspectivas de atuação. 1. ed. Curitiba: Appris Ltda., 2018.

NUNES, Gladys. Projeto Genesis estimula debate ambiental em escolas de Resplendor. 2012. Disponível em: www.intitutoterra.org. Acesso em: 20 maio 2018.

NUNES, Marilene. Institucionalização da educação ambiental no Brasil. Portal Ambiente Legal 2015.Disponível em:http://www.ambientelegal.com.br/educacao-ambiental-nobrasil/. Acesso em: 14 set. 2017. 
PASSOS, Manuela Gazzoni dos. Práticas em educação ambiental. Curitiba: Ed. Prismas, 2013. $86 \mathrm{p}$.

RAUBER, Marcos Eduardo. Apontamentos sobre a política nacional de resíduos sólidos, instituída pela Lei Federal n 12.305, de 02.08.2010. Electronic Journal of Management, Education and Environmental Technology (REGET), v. 4, n. 4, p. 01-24, 2011.

SANTOS, Miguel C. Jaguaripe: a primeira vila do Recôncavo - Bahia - Brasil. Disponível em: <http://www.jaguaripe.tur.br>. Acesso em: 25 maio 2016.

SILVA, Alessandra Tereza Mansur. Articulação entre educação ambiental e ensino da arte, como estratégia de preservação do manguezal. Joinville, 2007. Disponível em: www.livrogratis.com.br. Acesso em: 15 maio 2018.

SILVEIRA, Larissa Souza da; ALVES, Josineide Vieira. O uso da fotografia na educação ambiental: tecendo considerações. Pesquisa em educação ambiental, v. 3, n. 2, p. 125-146, 2008.

SATO, Michèle; PASSOS, Luiz Augusto. Arte-educação-ambiental. Ambiente \& Educação Revista de Educação Ambiental, v. 14, n. 1, p. 43-59, 2009.

TALAMONI, Ana Carolina B. et al. Histórico da educação ambiental e sua relevância à preservação dos manguezais brasileiros. In: PINHEIRO, Marcelo Antonio Amado;TALAMONI, Ana Carolina Biscalquini (Orgs.). Educação ambiental sobre manguezais. 1. ed. São Vicente: Campus do Litoral Paulista - Instituto de Biociências, 2018.

TAVARES, Jimy Carter Lima. Caracterização dos resíduos sólidos urbanos da cidade de Maceió - AL. 2008. 114 p. Dissertação (Mestrado em Engenharia: Recursos Hídricos e Saneamento) - Centro de Tecnologia, Universidade Federal de Alagoas, Maceió.

Recebido em: 08/12/2017 Aprovado em: 07/02/2019

Universidade do Estado de Santa Catarina - UDESC Centro de Ciências Humanas e da Educação - FAED

Revista PerCursos Volume 19 - Número 41 - Ano 2018 revistapercursos@gmail.com 